\title{
Erratum to: A Novel Treatment Schedule for Rapid Completion of Surgery and Radiation in Early-Stage Breast Cancer
}

Tina J. Hieken, MD ${ }^{1}$, Robert W. Mutter, MD $^{2}$, James W. Jakub, $\mathrm{MD}^{1}$, Judy C. Boughey, MD ${ }^{1}$, Amy C. Degnim, $\mathrm{MD}^{1}$, William R. Sukov, $\mathrm{MD}^{3}$, Stephanie Childs, $\mathrm{MD}^{2}$, Kimberly S. Corbin, $\mathrm{MD}^{2}$, Keith M. Furutani, PhD $^{2}$, Thomas J. Whitaker, PhD $^{2}$, and Sean S. Park, MD, PhD $^{2}$

${ }^{1}$ Department of Surgery, Mayo Clinic, Rochester, MN; ${ }^{2}$ Department of Radiation Oncology, Mayo Clinic, Rochester, MN; ${ }^{3}$ Department of Pathology and Laboratory Medicine, Mayo Clinic, Rochester, MN

\section{ERRATUM TO: ANN SURG ONCOL}

DOI 10.1245/S10434-016-5321-1

In the initial online publication, Robert W. Mutter's middle initial was incorrect. It has been corrected in the publication as shown in this erratum.

The online version of the original article can be found under doi: 10 . 1245/s10434-016-5321-1.

(C) Society of Surgical Oncology 2016

Published Online: 20 July 2016

T. J. Hieken, MD

e-mail: hieken.tina@mayo.edu 